Article

\title{
Impact of Biodiesel Blends and Di-Ethyl-Ether on the Cold Starting Performance of a Compression Ignition Engine
}

\author{
Adrian Clenci ${ }^{1,2, *}$, Rodica Niculescu ${ }^{1}$, Amélie Danlos ${ }^{2}$, Victor Iorga-Simăn ${ }^{1}$ and Alina Trică ${ }^{3}$ \\ 1 Department Automobiles and Transport, University of Pitesti, 1, Tg. din Vale street, Pitești 110040, Romania; \\ rodica.niculescu@upit.ro (R.N.); victor.iorga@upit.ro (V.I.-S.) \\ 2 Le Cnam Paris, Laboratoire de génie des procédés pour l'environnement l'énergie et la santé, \\ 292 rue St. Martin, Paris 75003, France; amelie.danlos@cnam.fr \\ 3 Renault Technologie Roumanie, 2, Bd. Pipera, Voluntari, Ilfov 077190, Romania; alina.trica@renault.com \\ * Correspondence: adi.clenci@upit.ro or adrian.clenci@cnam.fr; Tel.: +40-348-453-166 or +40-348-453-163
}

Academic Editor: Thomas E. Amidon

Received: 8 March 2016; Accepted: 6 April 2016; Published: 18 April 2016

\begin{abstract}
The use of biodiesel fuel in compression ignition engines has the potential to reduce $\mathrm{CO}_{2}$, which can lead to a reduction in global warming and environmental hazards. Biodiesel is an attractive fuel, as it is made from renewable resources. Many studies have been conducted to assess the impact of biodiesel use on engine performances. Most of them were carried out in positive temperature conditions. A major drawback associated with the use of biodiesel, however, is its poor cold flow properties, which have a direct influence on the cold starting performance of the engine. Since diesel engine behavior at negative temperatures is an important quality criterion of the engine's operation, one goal of this paper is to assess the starting performance at $-20^{\circ} \mathrm{C}$ of a common automotive compression ignition engine, fueled with different blends of fossil diesel fuel and biodiesel. Results showed that increasing the biodiesel blend ratio generated a great deterioration in engine startability. Another goal of this study was to determine the biodiesel blend ratio limit at which the engine would not start at $-20{ }^{\circ} \mathrm{C}$ and, subsequently, to investigate the impact of Di-Ethyl-Ether (DEE) injection into the intake duct on the engine's startability, which was found to be recovered.
\end{abstract}

Keywords: diesel fuel; biofuel; di-ethyl-ether; cold start; in-cylinder pressure

\section{Introduction}

\subsection{Policy Background}

According to [1], the European automotive industry is a key sector for the European economy, providing over 12 million jobs and a positive contribution to the trade balance of around $€ 90$ billion (in 2011), which is essential for continued European prosperity. It provides the means of transport for the large majority of passenger and freight movements.

From the road transport standpoint, today, there are three major problems facing humanity: (1) concerns about greenhouse gas (GHG) emissions and global climate change; (2) a desire for renewable/sustainable energy sources; and (3) an interest in developing domestic and more secure fuel supplies, in other words, energy security. These issues have led to intense debate within international organizations and among political leaders on the impacts of the increased use of biofuel [2].

Statistics from the European Commission (EC) highlight that the road transport sector is dominated by oil, which has proven reserves that are expected to last around 40 more years [3]. For instance, in 2010, in the European Union (EU), 94\% of energy consumption in the road transport sector came from oil, $84 \%$ of which was imported. The oil supply and, thus, EU mobility therefore largely 
depend on politically-unstable regions, which could affect the security of supply [4]. Furthermore, according to the International Energy Agency (IEA) report "Key World Energy Statistics", fossil fuels accounted in 2006 for over $80.3 \%$ of the primary energy consumed in the world, $57.7 \%$ of which was used in the transport sector [2].

The EU objective is to achieve an overall $80 \%-95 \%$ reduction in $\mathrm{CO}_{2}$ emissions by the year 2050 , with respect to the 1990 level. Decarbonization of transport and the substitution of oil as transport fuel therefore have both the same time horizon of 2050 [3]. The Final Report from 2012 of the CARS 21 High Level Group highlights that reducing $\mathrm{CO}_{2}$ emissions from road transport requires a comprehensive and integrated approach, including action by all stakeholders to improve vehicle efficiency, the use of sustainable alternative fuels and the decarbonization of the energy used [1]. In order to meet this policy objective, there is a need for a portfolio of alternative fuels, covering electricity, hydrogen, biofuels, methane, LPG (Liquid Petroleum Gas) and others [1]. Clearly, there is no single fuel solution for future mobility. These alternative fuels can therefore be called complementary fuels, as the future scenario will involve the coexistence of many fuels on the same market at the same time.

As argued in [3], the compatibility of new fuels with current vehicle technology and energy infrastructure or, alternatively, the need for disruptive system changes should be taken into account as important determining factors influencing the introduction of alternative fuels. Therefore, a supportive policy framework at the EU level and harmonized standards for biofuels across the EU are key elements for the future uptake of sustainable biofuels. According to the same report [3], all sectors of road transport, both for passengers and freight, could be covered by biofuels in liquid form, in all molecular compositions, if sufficient feedstock for sourcing can be made available. Technically, biofuels could replace oil in all transport modes, with existing power train technologies and existing re-fueling infrastructures. Biofuels are currently the most important type of alternative fuels, accounting for $4.4 \%$ of registered consumption in the transport sector in the EU [4]. They can contribute to a substantial reduction in global $\mathrm{CO}_{2}$ emissions if they are produced sustainably and do not cause indirect land use changes.

Thus, the European "Renewable Energy Directive" 2009/28/EC includes a binding target of 10 percent renewable fuels in transport in 2020 [5]. For vehicle owners, however, it is essential that fuels and vehicles operate in all climatic conditions.

\subsection{Types of Biofuels}

Currently, biofuels are referred to as either first or second generation. This terminology is in popular usage, but has no legal or regulatory meaning. Generally, the term "first generation" refers to biofuels produced from commonly-available, edible feedstocks using well-established conversion technologies. Most biofuels in use today are classified as "first generation". This includes ethanol produced via fermentation of sugars (from corn, sugar cane, sorghum, etc.) and biodiesel produced via transesterification of triglycerides (from vegetable oils and animal fats). The term "second generation" can refer to biofuels produced from either advanced, non-food feedstocks or produced via advanced processing technology (or both). Examples of advanced feedstocks include lignocellulose and nonedible triglycerides (such as jatropha and algae). Examples of advanced processing technology include catalytic hydro processing of triglycerides to produce renewable diesel and thermal conversion (gasification and pyrolysis) of lignocelluloses [6]. The production of biofuels from both food and energy crops is limited by the availability of land, water, energy and co-product yields, as well as sustainability considerations, such as the life-time accountancy of $\mathrm{CO}_{2}$ emissions. Second generation biofuels from waste and residues are also limited by the availability of these materials [3].

Liquid biofuels that are currently available on the market are mainly "first generation" biofuels. Blends with conventional fossil fuels are compatible with the existing fuel infrastructure, and most vehicles are compatible with currently-available blends (e.g., E10 = gasoline with $10 \%$ bioethanol and B7 = petroleum diesel fuel with $7 \%$ biodiesel). Blends with higher biofuel content may require adjustments of the powertrain and the development of specific standards [4]. 
The analysis of National Renewable Energy Action Plans (NREAPs) submitted by EU Member States in June 2010 [1] reveals that Member States intend to slightly overshoot the $10 \%$ target set by the European "Renewable Energy Directive" 2009/28/EC [5]. Thus, the EU member states intend 8.5\% to come from first generation biofuels, $1 \%$ from second generation biofuels and $1 \%$ from renewable electricity, most of the latter in railways rather than in cars. As in their national plans, Member States seem to be mostly counting on first generation biofuels; their sustainability is a key issue.

\subsection{Biodiesel}

Biodiesel is the name for a variety of ester-based oxygenated fuels from renewable biological sources. It can be used in compression ignition engines with little or no modifications [7]. Biodiesel is a multiple-component mixture of monoalkyl esters of long-chain Fatty Acids (FA) derived from vegetable oils and animal fats. Biodiesel fuel produced from transesterification of triglycerides contains numerous individual Fatty Acid Methyl Ester (FAME) species. Up to now, methanol has been the most widely-used alcohol to esterify FA, and the resulting product is called FAME. The biggest advantage of biodiesel over gasoline and petroleum diesel is its environmentally-friendly nature [8]. The name biodiesel was coined in the United States in 1992 by the National Soy Diesel Development Board (presently the National Biodiesel Board), which pioneered the commercialization of biodiesel in the United States. Biodiesel has better properties than petroleum diesel in that it is renewable, biodegradable, non-toxic and essentially free of sulfur and aromatics [7]. Biodiesel fuel has the potential to reduce the level of pollutants and $\mathrm{CO}_{2}$, which can lead to a reduction in global warming and environmental hazards $[7,9]$. The raw materials exploited commercially by biodiesel are the edible fatty oils derived from rapeseed, soybean, palm, sunflower, coconut and linseed [7]. However, there are two main problems associated with the use of biodiesel as an alternative to petroleum diesel fuel: its poor cold flow properties and thermal stability [9]. The former has a direct influence on the cold starting performance of the engine.

Since diesel engine behavior at low temperatures is an important quality criterion of the engine's operation, the goal of this paper is to assess the cold startability performance of a common automotive compression ignition engine, fueled with different blends of fossil diesel fuel and biodiesel. When the engine is unable to start, Di-Ethyl-Ether (DEE) is used as an ignition improver.

After this first section framing the study in the current fuel context, the remainder of the paper comprises two main sections. Section 2 presents the characterization of biodiesel and cold starting. This is followed in Section 3 by a description of the methodology used for the tests, the experimental facilities and the presentation of the results, which are discussed in detail. Finally, the conclusions drawn from the study are summarized.

\section{Biodiesel and Cold Starting}

\subsection{Biodiesel Characterization}

The Fatty Acid (FA) content of biodiesel is the major indicator of its properties. The physical and chemical properties of feedstocks (e.g., FA composition, free fatty acid content, moisture, impurities, etc.) influence both the biodiesel production process and the properties of the product. For instance, cetane number, flash point, oxidative stability, cloud point and heat content of biodiesel depend on the chain length and unsaturation of the constituent FA [10]. Biodiesel properties can therefore vary substantially from one feedstock to another. Singh et al. in their review [7] state that biodiesel properties can even vary for the same raw material depending on the plant part used. This is because the FA content in the different parts of plants is different in the same plant species.

A literature review revealed that the biodiesel properties reported by different authors vary considerably $[6,7,9,11]$. According to [6], this variation can be mainly attributed to the use of different analytical methods and different skill levels in applying these methods. Additional sources of 
variability include the chemical process used to produce the FAME, the clean-up process used to purify raw FAME and the storage time (and conditions) prior to analysis.

When reviewing the properties of biodiesel obtained from different feedstocks, it is useful to bear in mind the standard specifications established by different standardization organizations [12,13]. For instance, the American Society for Testing and Materials (ASTM) has established standard specifications for biodiesel fuel blendstocks (B100), called ASTM D6751, as well as for biodiesel blends of B6-B20 in petroleum diesel, called ASTM D7467. Blends of B5 and below are permitted under the standard specifications for petroleum diesel fuel, ASTM D975. Up to now, the European Committee for Standardization (CEN (Commission Européenne de Normalisation)) has only established standard specifications for B100, called EN 14214, but not for different levels of blends. Like the ASTM, the European standard specifications for conventional petroleum diesel fuel (EN 590) permit blends of B7 and below.

Most characteristics of biodiesel and its blends with petroleum diesel fuel are close to those of diesel fuel. This justifies the interest in using it as a substitute for fossil fuel. However, when using biodiesel blends in subzero ambient temperatures, their properties make engine starting more difficult. The following sub-sections briefly present the characteristics related to engine cold starting.

\subsubsection{Viscosity}

Viscosity, according to the international standard, is a measure of resistance to flow of a liquid due to internal friction of one part of a fluid moving over another, under the force of gravity. This is a critical property because it affects the behavior of fuel injection. As viscosity is impacted by ambient temperature, countermeasures must be taken in order to avoid deterioration of the engine operation. For instance, when trying to start the engine at very low ambient temperatures, due to the higher viscosity of the fuel, the engine may have difficulty starting.

High viscosity can cause larger droplet sizes, poorer fuel atomization and vaporization, narrower injection spray angle and greater in-cylinder penetration of the fuel spray. High viscosity can also reduce fuel flow rates, resulting in inadequate fueling. A very high viscosity may actually result in pump distortion, as well. According to [14], for temperatures at or below $-20^{\circ} \mathrm{C}$, the kinematic viscosity should be at or below $48 \mathrm{~mm}^{2} / \mathrm{s}$ to avoid potentially dangerous loads on the high pressure fuel pump drive system. Lastly, high fuel viscosity leads to overall poorer combustion, higher emissions and increased oil dilution.

Among the general parameters for biodiesel, the viscosity of FAME can reach very high levels, and hence, it is important to control it within an acceptable range to avoid negative impacts on the fuel injectors' system performance.

Generally, biodiesel fuel blends have a higher viscosity than petroleum diesel fuel.

\subsubsection{Density}

Fuel density is another key property that affects engine performance. Because fuel is metered by volume, not by mass, a greater or lesser mass of fuel is injected depending on its density. Thus, the air-fuel ratio and energy content within the combustion chamber are influenced by fuel density.

Density increases when the ambient temperature lowers; therefore, like viscosity, it affects the engine cold starting performance.

In general, the densities of biodiesel fuels are slightly higher than those of petroleum diesel fuel. Density increases when the level of biodiesel increases; the specific values depend on FA composition and purity. Contamination by some unwanted compounds can significantly affect FAME density [14].

\subsubsection{Cetane Number}

Cetane Number $(\mathrm{CN})$ is the main indication of the auto-ignition and combustion quality characteristics of the fuel used in a diesel engine. It affects cold startability, combustion stability 
and noise. A higher $\mathrm{CN}$ generally decreases engine cranking time (the time before the engine reaches "starter off") by decreasing the ignition delay.

According to [6], since biodiesel is largely composed of long-chain hydrocarbon groups (with virtually no branching or aromatic structures), it typically has a higher $\mathrm{CN}$ than petroleum diesel fuel, and increasing the Biodiesel (B) level of biodiesel blends increases the $\mathrm{CN}$ of the blend. As shown by [15], the CN of biodiesel fuels is considerably influenced by their FAME composition. Hence, by knowing the FAME composition alone, nearly all of the properties of biodiesel can be predicted.

Generally, whatever the feedstock used for its production, biodiesel has a higher $\mathrm{CN}$ than petroleum diesel fuel.

\subsubsection{Distillation Characteristics}

The Distillation Curve (DC) indicates the amount of fuel that boils off at a given temperature. The curve can be divided into three parts: (1) as in the beginning, only the light fractions of the fuel boil, the first region can be called the light end; it affects startability and is usually characterized by the temperature at which $10 \%$ of the fuel has boiled (T10); (2) the region around the $50 \%$ evaporated point, characterized by the T50; (3) the heavy end (i.e., boiling of the heaviest fuel fractions), which is usually characterized by the T90 or T95 and has been the most thoroughly studied with respect to its effect on tailpipe emissions [16]. The DC indicates the overall volatility of the entire fuel product, which affects, amongst other engine characteristics, the cold startability.

In general, biodiesel fuel blends boil off at higher temperatures than conventional diesel fuel.

\subsubsection{Cold Flow Characteristics}

One of the most fundamental quality criteria for compression ignition engine fuels is the cold flow characteristics, which are primarily dictated by: (1) fuel distillation range, mainly the light-end volatility; (2) hydrocarbon composition: content of paraffins, naphthenes, aromatics; (3) use of cold flow additives.

The mechanism of cold flow properties was well explained by Dwivedi and Sharma [8]: at low temperature engine operation, fuel gelling takes place, which results in crystallization of the molecules of the liquid. For crystallization to occur, the molecules of the liquid must generate sufficient thermodynamic force by the strong intermolecular force of interaction. This thermodynamic force is generated when the temperature of the liquid is reduced toward its freezing point. Crystallization of the fuel may cause fuel "starvation" and operability problems as solidified material clogs fuel lines, the fuel pump, filters and injectors. Therefore, the most important considerations for users of diesel engines at subzero temperatures are the cold flow characteristics of the fuel.

Low-temperature operability of diesel engines is normally determined by three fuel parameters: Cloud Point (CP), Cold Filter Plugging Point (CFPP) and Pour Point (PP). When the liquid fuel is subjected to cooling, the above parameters can be defined as follows:

- $\quad \mathrm{CP}$ is the temperature at which a clear liquid product becomes cloudy, i.e., when solid particles appear (crystals of alkanes and microcrystals of ice);

- CFPP is the lowest temperature at which a given volume of diesel engine fuel type still passes through a standardized filtration device in a specified time. In the USA and Canada only, the Low Temperature Flow Test (LTFT) was developed to predict how diesel engine fuels will perform at low temperatures [16]. LTFT is a slow cooling test and is more severe than CFPP;

- $\quad \mathrm{PP}$ is the lowest temperature at which the fuel will cease to flow.

Because of large seasonal and geographic temperature variability, neither the USA, nor European biodiesel standards have firm specifications for these low temperature properties, though they are among the most important properties in determining the suitability of biodiesel fuels in-use [8]. Therefore, diesel engine fuel cold flow properties must be specified according to the seasonal and climatic needs in the region where the fuel is to be used [16]. 
According to [8], the cold flow properties of biodiesel are dictated by the length of the hydrocarbon chains and the presence of unsaturated FA in biodiesel. In their work, Dwivedi and Sharma [8] made a comprehensive analysis of the impact of biodiesel cold flow properties on engine performance, showing that for biodiesel (no matter what the feedstock), the cold flow characteristics are worse. Consequently, the higher the percentage of biodiesel in petroleum diesel-biodiesel blends, the worse the cold flow properties of the resulting fuel will be.

\subsubsection{Water Content}

The fuel should be clear in appearance and free of water, which can plug fuel filters at negative temperatures, leading to engine fuel starvation. Water accelerates oxidation, increases corrosivity and promotes microbial growth. Since FAME is capable of absorbing significantly more water than petroleum diesel fuel, it is especially important to dehydrate it during production and to minimize the potential to create free water during blending or distribution [14].

\subsection{Cold Starting}

Engine startability is the aptitude of an engine to start within a specified duration and to continue to run without faltering or assistance of the starting motor [17].

A cold engine starting may be defined as an event when the engine is started while the temperature of all its fluids and parts is equal to the ambient temperature. It represents a significant challenge in terms of forming combustible mixtures, and this becomes increasingly problematic when the ambient temperature decreases.

According to $[18,19]$, diesel engine startability is affected by many in-cylinder interacting physical and chemical processes, which lead to auto-ignition and, thus, to combustion. Physical processes include fuel injection, atomization, vaporization and, in the end, mixing of the fuel vapor with air. Chemical processes include the decomposition reactions of the fuel, the formation of radicals in critical concentrations and the formation of ignition nuclei.

When trying to start a diesel engine at low ambient temperature, frictional losses increase owing to the increased lubricating oil viscosity. Thus, in the very first cycles, one may expect a lack of sealing oil film between the piston and the cylinder liner; combined with the low starter speed, this causes an air leakage, which, in turn, favors misfiring and partial firing cycles. These increase the starting time.

If taking the temperature at which emissions under cold operating conditions are regulated in Europe $\left(-7^{\circ} \mathrm{C}\right)$, current diesel engines' starting characteristics are quite good. In fact, the problem of cold starting is at issue at still lower temperatures (e.g., toward $-20^{\circ} \mathrm{C}$ and, sometimes, even below). Worldwide, there are many areas where this kind of subzero ambient temperature is encountered during winter (countries at high latitudes, regions at high altitudes and far from the moderating effect of the open sea). In this case, the start time and repeatability become the key performance attributes [20].

When blending fossil diesel fuel with some proportions of biodiesel, in spite of a greater CN of the resulting fuel (see Section 2.1.3), cold start deteriorates due to a thicker fuel and to its poorer capacity to vaporize (see Sections 2.1.1, 2.1.2 and 2.1.4). Certainly, the higher the biodiesel blend ratio, the worse for the cold startability. Since the trend is towards gradually increasing the percentage of biodiesel mixed with conventional petroleum diesel fuel (see Section 1.1), diesel engine cold starting requires special care, as it may reflect negatively on diesel engine market acceptance and practical use.

Speaking of market acceptance, one of its vectors is the engine's specific power, whose increase mainly relies on increasing the compression ratio within the air compressor from the turbocharger system. Thus, in order to limit the mechanical stress on engine parts, a corresponding decrease in the engine's volumetric compression ratio is required, which will certainly impair cold startability.

Moreover, due to the new Euro 6 standard, which aims at a significant reduction in $\mathrm{NO}_{x}$ emissions, manufacturers may decide to further reduce the engine's volumetric compression ratio in order to lower the temperature peaks responsible for the formation of $\mathrm{NO}_{x}$. An example in this direction 
is the current diesel engine family of the Mazda automotive manufacturer, which is based on an unprecedented reduction of the volumetric compression ratio $(\mathrm{VCR}=14)$ that complies with the Euro 6 legislation without calling for expensive post-treatments, such as Selective Catalyst Reduction (SCR) or a Lean $\mathrm{NO}_{x}$ Trap (LNT). Obviously, this can only intensify the problem of diesel engines' cold starting.

Taking into account the increasing popularity worldwide of the diesel engine, special attention needs to be paid to its cold starting performance, i.e., arrangements have to be made to improve its cold startability. For instance, [21] presents a bibliographical study on specific starting aids, such as: ceramic glow plugs, a preheating system of the aspirated air, intake manifold burners/thermo-starters, ether injection, oil pan heaters, fuel heaters (within the fuel tank/filter/injector), oxygen-enriched intake air, reverse exhaust flow by keeping one exhaust valve slightly open during the intake stroke, etc.

Many researchers have studied the cold starting of the petroleum diesel-fueled compression ignition engine [17-20]. To the authors' knowledge, however, there are only a few studies focusing on the assessment of the impact of biodiesel blends on the compression ignition engine cold startability. For instance, Broatch et al. [22] approached this subject showing that at $0,-5$ and $-10^{\circ} \mathrm{C}$, the engine's starting performance deteriorated when the blend ratio was increased. Moreover, in order to improve the cold flow characteristics of biodiesel blends based fuels, the same researchers [22] mention the use of specific additives (e.g., a very low content of olefin-ester copolymer of around $0.03 \%$ decreases the dynamic viscosity of soybean biodiesel by $33 \%$ ) or suggest blending the given biodiesel with other fuels, such as ethanol or kerosene (e.g., such a blend with ratios up to $20 \%$ of ethanol or kerosene also decreases the kinematic viscosity by $30 \%$ and promotes fuel atomization). The same ideas were found in $[23,24]$, which state that the most acceptable option to make the biodiesel available as a stand-alone fuel alternative to ordinary diesel is with the use of additives. Amongst other additives (ethanol and butanol), Obed et al. [23,24] used DEE with success in order to make biodiesel more suited for subzero temperatures. On the other hand, Kim et al. [25] evaluated not only the cold startability, but also the drivability after the engine started. They used a passenger car and a light duty truck fueled with different biodiesel blends (B5, B10, B20) of six different feedstocks. Their cold starting tests were performed in a chassis dynamometer at -16 and $-20{ }^{\circ} \mathrm{C}$ and showed mainly the influence of the feedstock upon the cold starting. Karmakar et al. [10] showed that the feedstock influences many of the cold flow properties of biodiesel blends and, thus, the cold starting performance of the engine.

In this framework, the aim of the present paper was to experimentally assess the effects of increasing the biodiesel blend ratio on the starting performance at $-20^{\circ} \mathrm{C}$ of a common automotive compression ignition engine. Furthermore, when the engine is no longer capable of starting, the impact of using DEE as an ignition improver was assessed.

\section{Experimental Setup}

\subsection{Methodology}

In order to assess the impact of the biodiesel blend ratio on the cold start performance of a diesel engine, the following methodology was used:

1. Production and characterization of pure biodiesel (B100) and the fuels used in the tests in the Laboratory of Chemistry at the University of Pitesti.The pure biodiesel (B100) was obtained from the catalytic transesterification of natural esters contained in sunflower oil, in the presence of ethyl alcohol and sodium hydroxide. The following step was to mix it with commercial petroleum diesel fuel in order to obtain different blends, such as B30 and B50. The diesel fuel used for blending is a commercial one and was acquired from a local fuel producer. It is specific for the winter season and, therefore, is free of any content of biodiesel. Its characteristics listed in Table 1 are provided by the producer, and some of them (CFPP, density and viscosity) are according to the requirements for "arctic" climatic zones for Classes 0 and $1[12,13]$. Concerning the characteristics of all of the above-mentioned blended fuels, they were then determined. Table 1 provides a side-by-side listing of the characteristics of the fuels used and the existing specifications with 
standard, test method and limits (where applicable). Furthermore, based on the review performed by Hoekman et al. [6], the properties of B100 from sunflower oil are given as a result of averaging the values from 20 cited references. Equally, based on the formulae found in [26,27], the values of density and kinematic viscosity were calculated at $-20^{\circ} \mathrm{C}$.

2. Assessing the cold starting performance of a common automotive compression ignition engine by experimental investigation during starting tests at $-20{ }^{\circ} \mathrm{C}$, in the following conditions:First, in order to create the reference, commercial petroleum diesel fuel was used. Then, the same tests were performed for B30 and B50. Tests were carried out with the baseline engine calibration within ECU so as to ensure that any modification of the starting performance was caused by the fuel itself and not by differences in engine settings.For temperature homogeneity reasons, before each test, the engine was kept inside the cold room at $-20{ }^{\circ} \mathrm{C}$ for $12 \mathrm{~h}$. Each of the 3 fuels used in the tests was kept in the cold room to ensure their temperatures were the same as the ambient temperature before beginning the tests. Furthermore, in order to be sure that in a test, the engine uses only the intended fuel, after each test, the fuel circuit was emptied by removing the fuel feed pipe from the tank and by letting the engine run until it stopped. Afterwards, the used fuel filter was replaced with a brand new one, and the engine was run at high speed with the new fuel until its oil temperature reached about $80^{\circ} \mathrm{C}$. Then, after $12 \mathrm{~h}$ at $-20^{\circ} \mathrm{C}$ a new measurement session was performed. Concerning the battery, for each test, a fully-loaded one was used. Thus, as before, every precaution was taken in order to ensure that any modification of the starting performance was caused by the fuel itself and not by other parameters, such as battery state of charge.The purpose of the study was also to obtain the biodiesel blend ratio limit at which the engine would not start at $-20^{\circ} \mathrm{C}$ and, subsequently, to investigate the effect of DEE injection into the engine intake duct on the engine's startability.

Table 1. Characteristics of the fuels used in the tests.

\begin{tabular}{|c|c|c|c|c|c|c|c|c|}
\hline \multirow{2}{*}{\multicolumn{2}{|c|}{$\begin{array}{ll}\text { Fuel } & \text { Properties } \\
\end{array}$}} & \multirow{2}{*}{ Diesel } & \multirow{2}{*}{ B30 } & \multirow{2}{*}{ B50 } & \multirow{2}{*}{ B100 } & \multirow{2}{*}{ B100 [6] } & \multicolumn{2}{|l|}{ Specifications } \\
\hline & & & & & & & (Fuel) Standard/Test Method & Limits * \\
\hline \multicolumn{2}{|c|}{ Density at $15^{\circ} \mathrm{C}\left(\mathrm{kg} / \mathrm{m}^{3}\right)$} & 841 & 860 & 880 & 896 & 878 & $\begin{array}{l}\text { (DIESEL) EN590/EN } 4264 \\
\text { (B100) EN 14214/EN } 3675\end{array}$ & $\begin{array}{l}820-845 \\
860-900\end{array}$ \\
\hline \multicolumn{2}{|c|}{ Density at $-20^{\circ} \mathrm{C}\left(\mathrm{kg} / \mathrm{m}^{3}\right)^{* *}$} & 872.2 & 886.9 & 896.7 & 921.3 & - & - & - \\
\hline \multicolumn{2}{|c|}{$\begin{array}{l}\text { Kinematic viscosity at } 40{ }^{\circ} \mathrm{C} \\
\qquad\left(\mathrm{mm}^{2} / \mathrm{s}\right)\end{array}$} & 2.53 & 3.5 & 3.9 & 5.1 & 4.42 & $\begin{array}{c}\text { (DIESEL) EN 590/EN } 3104 \\
\text { (B100) EN 14214/EN 3104-3105 } \\
\text { (B100) ASTM D 6751-08/D } 445\end{array}$ & $\begin{array}{l}2.0-4.5 \\
3.5-5.0 \\
1.9-6.0\end{array}$ \\
\hline \multicolumn{2}{|c|}{$\begin{array}{l}\text { Kinematic viscosity at }-20^{\circ} \mathrm{C} \\
\left(\mathrm{mm}^{2} / \mathrm{s}\right)^{* *}\end{array}$} & 9 & 15.5 & 19.9 & 30.7 & - & - & - \\
\hline \multicolumn{2}{|c|}{ Cloud point $\left({ }^{\circ} \mathrm{C}\right)$} & -12 & -9 & -6 & 1 & 2 & - & - \\
\hline \multicolumn{2}{|c|}{ Cold filter Plugging point $\left({ }^{\circ} \mathrm{C}\right)$} & -24 & -21 & -19 & -3 & -2 & - & - \\
\hline \multicolumn{2}{|c|}{ Water content $(\%)$} & 0.009 & 0.025 & 0.042 & 0.054 & - & $\begin{array}{c}\text { (DIESEL) EN590/EN12937 } \\
\text { (B6-20) ASTM D7467-08/D2709 } \\
\text { (B100) EN14214/EN12937 } \\
\text { (B100) ASTM D6751-08/D2709 }\end{array}$ & $\begin{array}{l}\text { Max. } 0.02 \\
\text { Max. } 0.05 \\
\text { Max. } 0.05 \\
\text { Max. } 0.05\end{array}$ \\
\hline \multirow[b]{2}{*}{$\begin{array}{l}\text { Distillation } \\
\text { characteristics }\end{array}$} & $\mathrm{T} 10\left({ }^{\circ} \mathrm{C}\right)$ & 191.4 & 201.2 & 209 & - & - & - & - \\
\hline & $\mathrm{T} 90\left({ }^{\circ} \mathrm{C}\right)$ & 324.6 & 350 & 354 & - & - & $\begin{array}{c}\text { (DIESEL) ASTM D975/D86 } \\
\text { (B6-20) ASTM D7467-08/D86 } \\
\text { (B100) ASTM D6751-08/D7501 }\end{array}$ & $\begin{array}{l}\text { Max. } 338 \\
\text { Max. } 343 \\
\text { Max. } 360\end{array}$ \\
\hline \multicolumn{2}{|c|}{ Lower heating value $(\mathrm{MJ} / \mathrm{kg})$} & 42.3 & 41.1 & 40.3 & 38.2 & 35.3 & - & - \\
\hline
\end{tabular}

* These limits correspond to the requirements for "temperate" climatic zones; ** predicted values. 


\subsection{Engine Configuration and Data Acquisition System}

The diesel engine submitted to the cold starting tests was a common rail, direct injection, turbocharged engine whose main technical data are presented in Table 2.

Table 2. Engine data.

\begin{tabular}{cc}
\hline Number of Cylinders & 4 \\
Engine displacement $\left(\mathrm{cm}^{3}\right)$ & 1461 \\
Volumetric compression ratio & 17.9 \\
Maximum power (kW)@speed (rpm) & $48 @ 4000$ \\
Maximum torque (Nm)@speed (rpm) & $160 @ 1700$ \\
Number of injector holes/hole diameter (mm) & $5 / 0.15$ \\
Injection pressure range (bar) & $100-1400$ \\
\hline
\end{tabular}

The cold starting performance of the engine was assessed mainly by analyzing two parameters during the cranking, stabilizing and idling stages:

1. engine speed;

2. in-cylinder instantaneous pressure.

As far as speed evolution is concerned, Figure 1 shows the main parameters used to analyze cold startability.

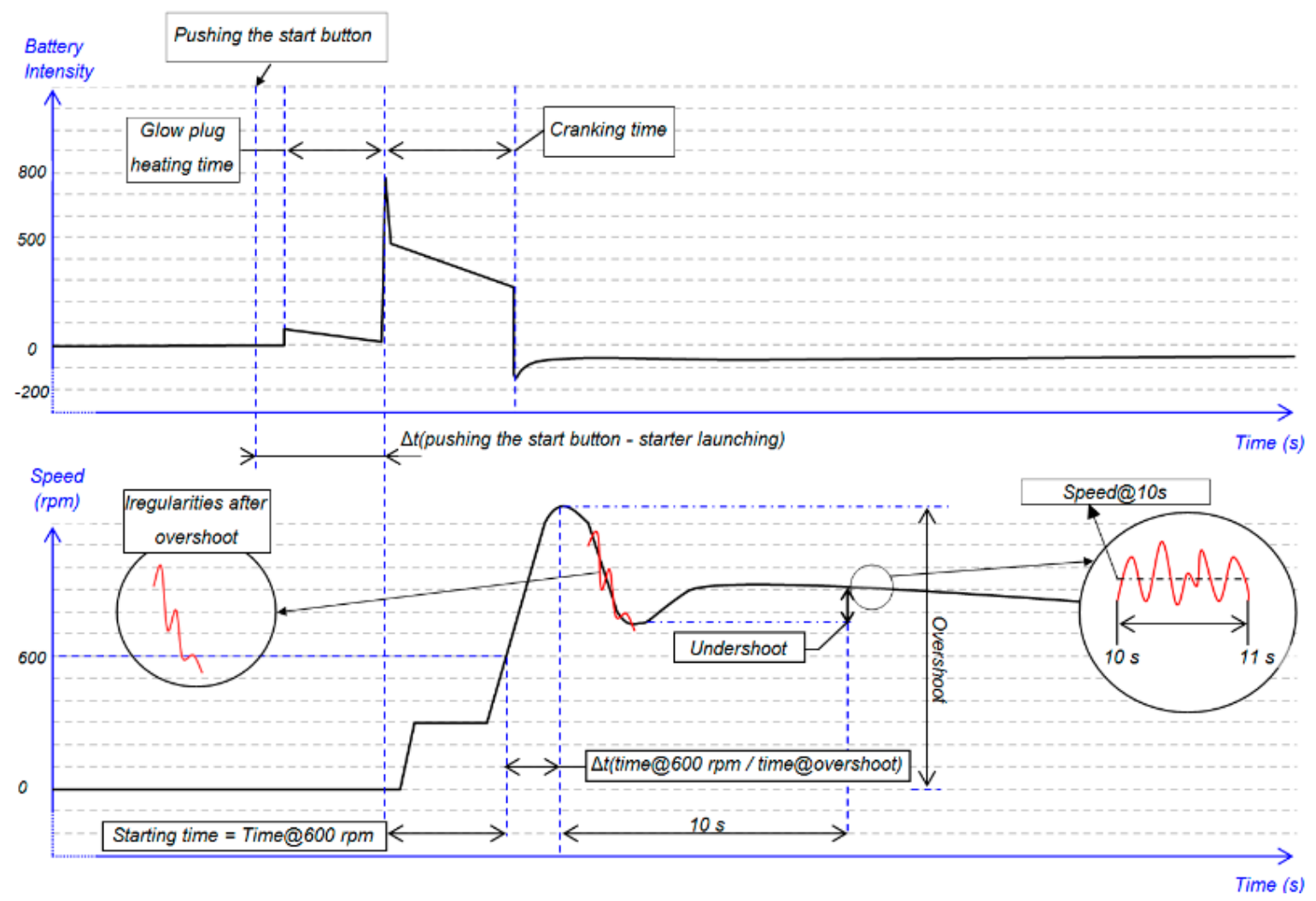

Figure 1. Engine behavior during cold start.

Here:

- $\quad$ starting time = time@600 rpm = time until $600 \mathrm{rpm}$ is reached (it is considered that once the engine reaches this speed threshold, it will be able to run unassisted/autonomously); 
- $\quad$ overshoot $=$ the maximum speed recorded during the start process;

- $\quad$ ramping time = time to reach overshoot from $600 \mathrm{rpm}$;

- $\quad$ speed@10 s = speed after $10 \mathrm{~s}$ from the overshoot (it should be near the idle target);

- $\quad$ undershoot = speed@10 s, the minimum recorded speed after overshoot.

Engine speed and other parameters used to assess the engine cold startability were acquired directly from the ECU (Engine/Electronic Control Unit) using INCA software. The current intensity during the test was measured with an AVL active current clamp featuring an accuracy of 3\%. The analysis of ECU-related parameters was performed with INCA's MDA (Measure Data Analyzer) software.

Secondly, in order to be able to acquire the instantaneous in-cylinder pressure, an AVL GU21C uncooled piezoelectric pressure transducer (measuring range: max. 250 bar; sensitivity: $16 \mathrm{pC} / \mathrm{bar}$; linearity error $\pm 0.3 \%$ FSO (Full Scale Operation); temperature range: $-40-400{ }^{\circ} \mathrm{C}$ ) was installed in the cylinder head, in the area corresponding to Cylinder Number 4 . The information provided by the pressure transducer was coupled with that coming from an AVL 365C angle encoder (max. speed: 20,000 rpm; sensitivity: up to $0.025^{\circ} \mathrm{CA}$; temperature range: $-40-100^{\circ} \mathrm{C}$ ) in order to obtain in-cylinder pressure diagrams, which were used to closely analyze the successive engine cycles during the tests. Data acquisition and the analysis of cycle-related parameters were performed with the complete AVL Indicom Hardware and AVL Concerto software (AVL, Graz, Austria).

During the tests, the above parameters were acquired during the cranking, stabilizing and idling phases. First, 200 complete engine cycles were acquired, starting with the moment of engine starter actuation. Then, after the engine had started, another sampling of 200 engine cycles was acquired to analyze the quality of the engine running.

In sum, the impact of biodiesel blend ratio and DEE on the engine's cold startability was analyzed through the following time-resolved data: ECU-related parameters (instantaneous engine speed, battery voltage and mass of injected fuel), absorbed current intensity and instantaneous in-cylinder pressure. All of these data were analyzed during the cranking, stabilizing and idling stages in order to draw a conclusion about what happens when increasing the biodiesel percentage.

\subsection{Results and Discussion}

For each of the tests performed (commercial petroleum diesel fuel, B30, B50), the glow plug states were the same, i.e., all off, preheat, wait for cranking, cranking, post heat on, post heat finished. As will be seen below, the engine did not manage to start with $\mathrm{B} 50$. Therefore, as already mentioned, the solution used to help the engine to start was the injection of di-ethyl-ether (DEE: $\mathrm{CH}_{3} \mathrm{CH}_{2}-\mathrm{O}-\mathrm{CH}_{2} \mathrm{CH}_{3}$ ) into the intake duct just before the air filter and before pushing the engine's start button. The DEE stored in an accumulator was injected upstream the air filter at a pressure of 1 bar. An in-house built electronic circuit was used to control the DEE flow rate.

The low viscosity $\left(0.23 \mathrm{~mm}^{2} / \mathrm{s}\right)$, auto-ignition $\left(160^{\circ} \mathrm{C}\right)$ and boiling temperature $\left(34.6^{\circ} \mathrm{C}\right)$, high $\mathrm{CN}(>125)$ and volatility of DEE are the reasons for selecting it as an ignition improver in diesel engines [28-30]. Since DEE is extremely flammable (e.g., in dry air, even in a flame-free environment, explosive peroxides may be formed), for this particular case consisting of performing a cold starting test with DEE injection, the glow plugs were disabled in order to avoid violent and destructive combustion inside the cylinders. As pointed out by [29], there are very few studies on the use of DEE in diesel engines.

Figures 2 and 3 show the evolution of the battery voltage and absorbed current intensity during the cold starting tests. 


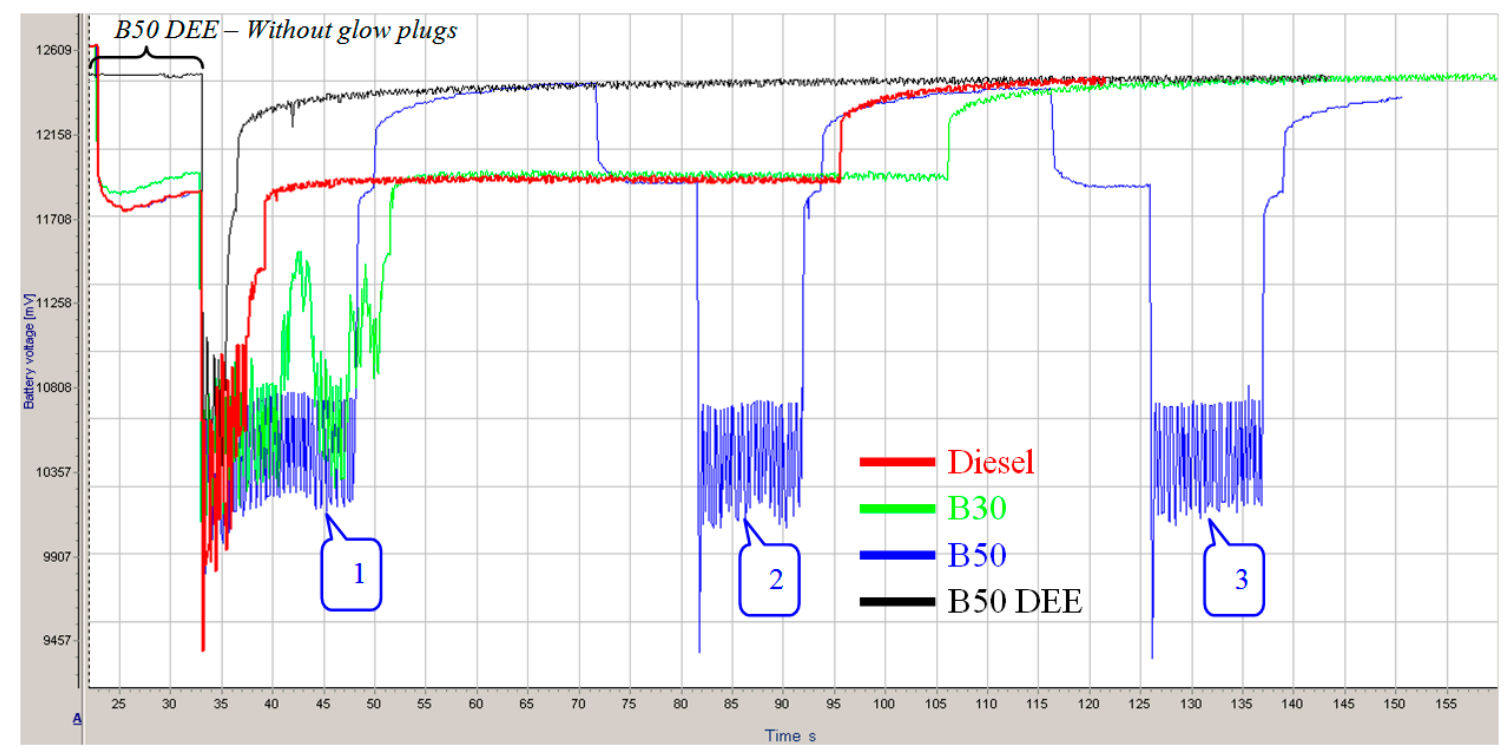

Figure 2. Battery voltage evolution.

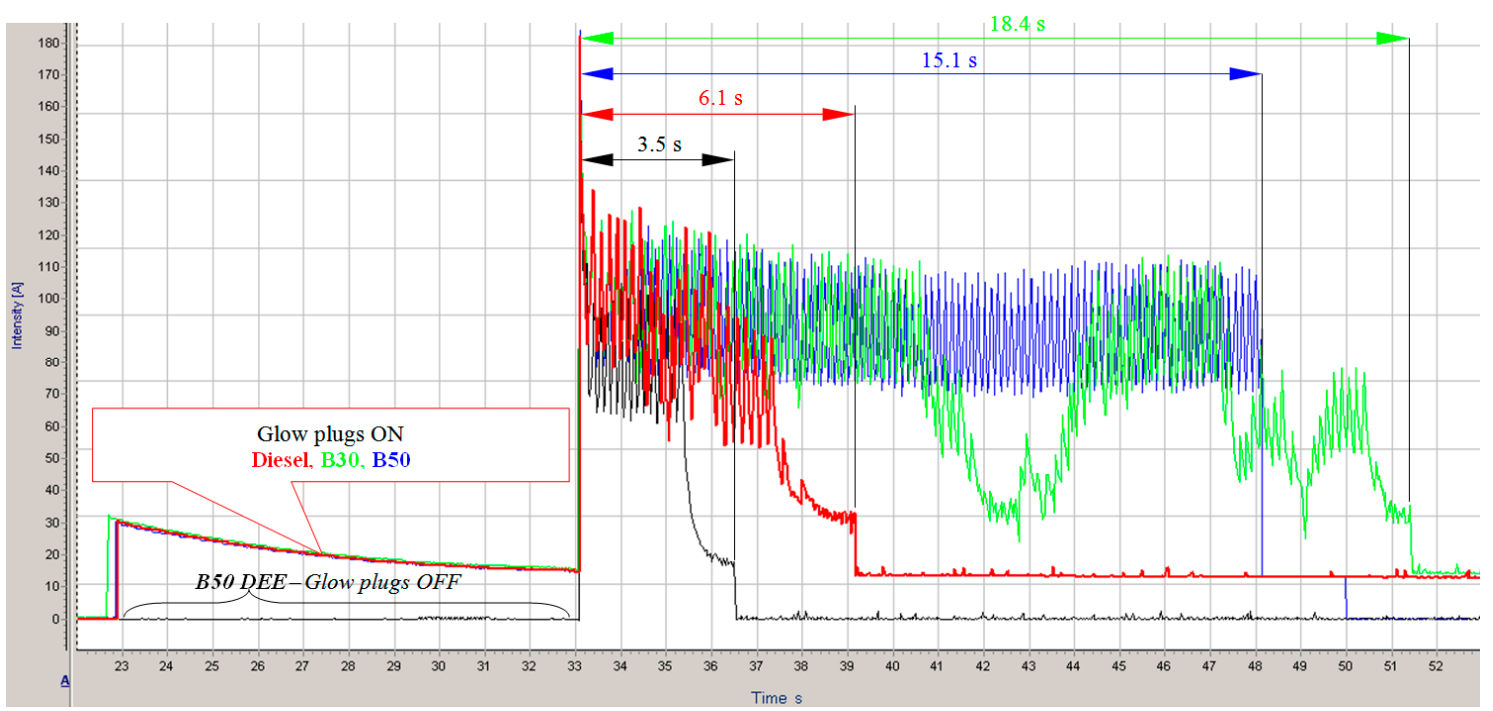

Figure 3. Absorbed current intensity evolution.

In Figure 2, for diesel fuel, B30 and B50, it can be seen that there is an initial fall in battery voltage caused by actuating the glow plugs. The second fall is generated by the actuation of the starter electric motor. This is the cranking phase, whose duration can be clearly observed in Figure 3. It is obvious that the engine achieves the lowest starting time when using B50 with DEE injection (B50_DEE).

Furthermore, with respect to commercial petroleum diesel fuel (red curves), the cranking time increases significantly when using B30 (green curves). The fluctuations of the absorbed current intensity in the B30 case show the "hesitations" encountered by the engine while trying to run unassisted. With B50 (blue curves), in spite of a longer cranking time (15.1 s), the engine fails to start. The other two attempts to start the engine with B50 were equally unsuccessful (see the following two falls in battery voltage in Figure 2).

The engine speed evolution during the cranking, stabilizing and idling stages for each type of fuel used in our tests is presented in Figure 4. 


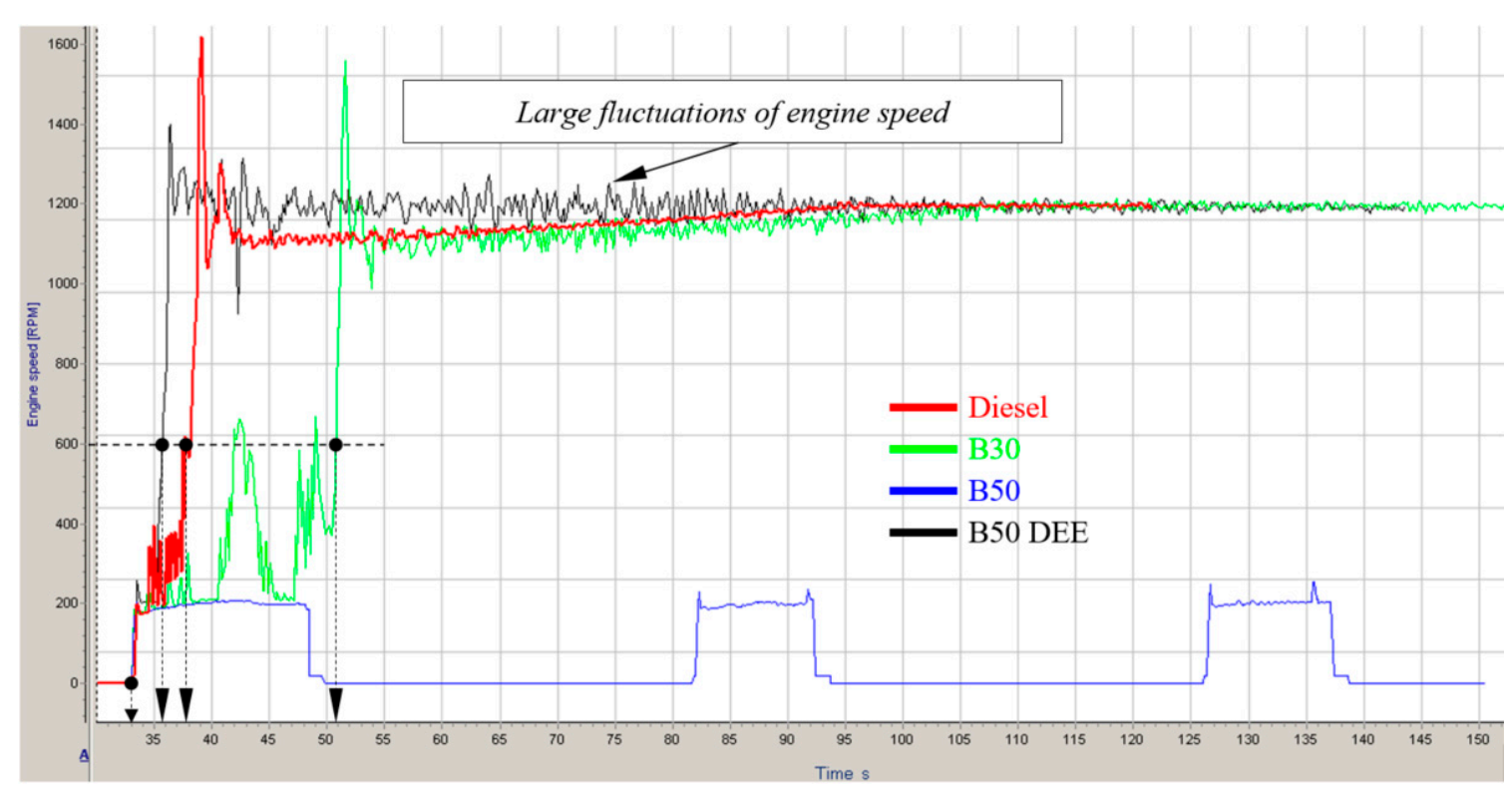

Figure 4. Engine speed evolution.

Starting from the information presented in Figure 4, the parameters described by Figure 1 were extracted and are illustrated in Figure 5.

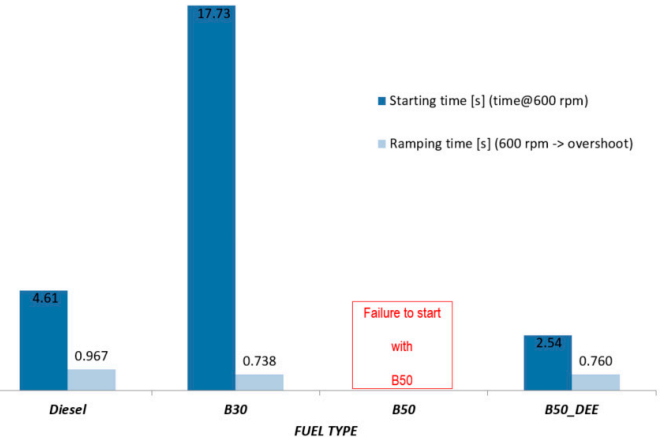

(a)

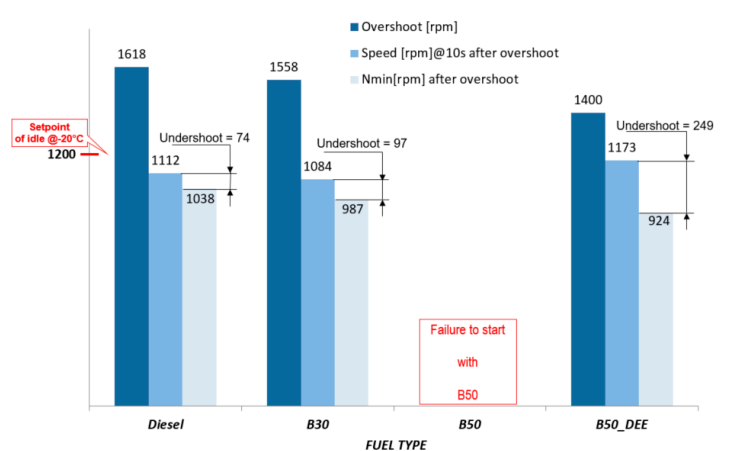

(b)

Figure 5. Speed-related parameters used to assess the engine cold starting performance: (a) speed evolution over time; (b) specific speeds.

Looking at the fluctuation of the engine speed for B30 in Figure 4, we observe that the engine twice exceeds the speed threshold of $600 \mathrm{rpm}$ before actually starting. Therefore, in this case, the starting time or the time required to exceed the threshold of $600 \mathrm{rpm}$ is almost 4-times larger than when using diesel fuel (Figure 5a).

The overshoot for B30 and B50 with DEE injection is lower than for diesel fuel (Figure 5b). Consequently, the ramping time or the time required to reach overshoot from the speed threshold of $600 \mathrm{rpm}$ is also lower for B30 and B50 with DEE injection than for diesel fuel (Figure 5a).

In order to explain the above results, Figure 6 shows the evolution of the mass of fuel injected, where it can be seen that the mass of fuel injected for B50 with DEE injection and B30 is smaller than in the case of diesel fuel (see the injection time illustrated by the horizontal arrows on this figure).

For the B30 case, from Figure 6 is taken only the last injection peak before the engine starts. If we add the higher tendency of diesel fuel to vaporize compared to biodiesel (see Table 1), then it is obvious that the greater overshoot value for diesel is generated by the greater mass of burning fuel. 


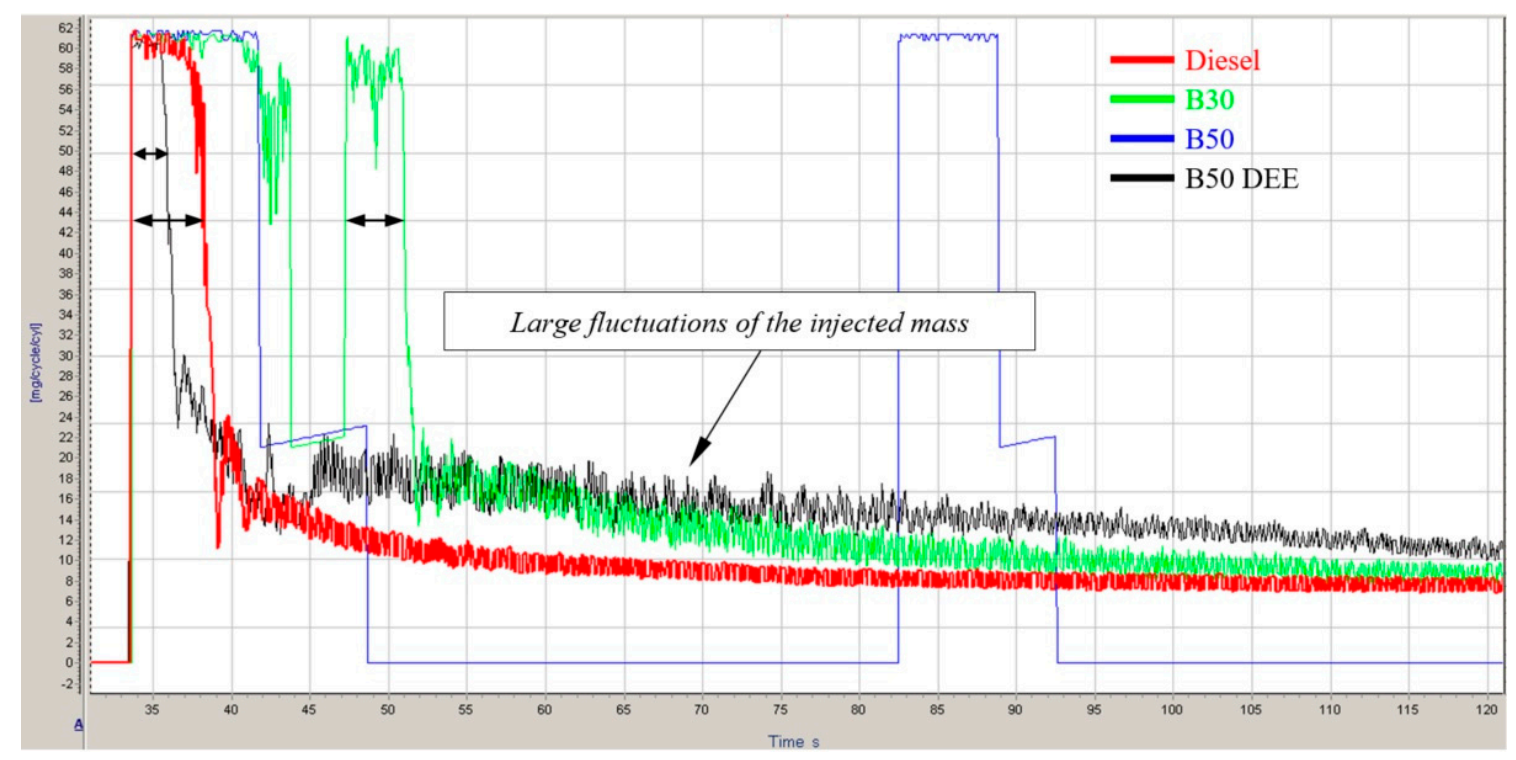

Figure 6. Evolution of the mass of injected fuel.

Figure 5 shows that the undershoot increases with the increase in biofuel percentage. This reflects the stability of the engine operation, which deteriorates with the addition of biofuel.

Regarding the effect of the injected DEE, due to a clear upward evolution of engine speed (see the black curve in Figure 4), which is caused by inflammation of the injected DEE, the injected mass of B50 is smaller (Figure 6). However, after the engine starts, fluctuations in the engine speed are observed (Figure 4), which the ECU attempts to diminish by a corresponding actuation of the injectors (Figure 6).

Analysis of the engine speeds (Figure 4) shows that for all three cases, the idle set point is reached at around $105 \mathrm{~s}$. At this time, as can be seen in Figure 6, the mass of injected fuel differs. Therefore, the more biofuel is added, the more must be injected to achieve the same idle speed (1200 rpm). Consequently, even if the lower heat value decreases with increasing biofuel percentage (see Table 1), the heat generated per cycle and cylinder increases. Assuming that the actual work is the same in the three cases analyzed, the engine speed being the same, then the obvious conclusion is that with the addition of biofuel, the engine efficiency deteriorates. This conclusion was also reported by Mattarelli et al. [31], who investigated the effect of using different blends of rape-seed biodiesel on engine performances.

In order to continue the analysis of the cold starting, as mentioned before, we monitored the in-cylinder instantaneous pressure evolution. In Figure 7a,b, the succession of Engine Cycles 5-8 (during the first 4 engine cycles, due to the inherent strong engine vibrations, problems with synchronizing the pressure signal with the one coming from the angle encoder occurred) is shown for the case of diesel fuel, B30 and B50 with DEE injection. For diesel fuel, it is seen that the seventh engine cycle is the first cycle with combustion. For the case of B50 with DEE injection, the fifth motor cycle is the first cycle with combustion.

Analyzing the pressure peaks (Pmax), one can see there is quite a significant difference: 136.9 bar for diesel fuel at the 12th cycle, 131.3 bar for B30 at the 50th cycle and 214.3 bar for B50 with DEE injection at the 5th cycle (Figure 8).

Returning to the effect of DEE on engine behavior, Figures $7 \mathrm{~b}$ and 8 show that two cycles with very high peak pressures ( $>200$ bar) were recorded. The amount of DEE that was injected into the air filter inlet was $150 \mathrm{mg}$. As seen, it was enough to help the engine to start, but at the cost of generating extreme mechanical stress. It is for this reason that the actuation of glow plugs is not recommended when using DEE as the ignition improver. 


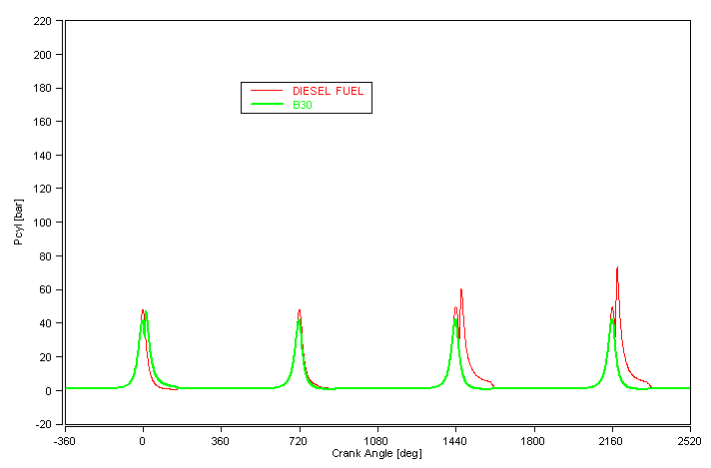

(a)

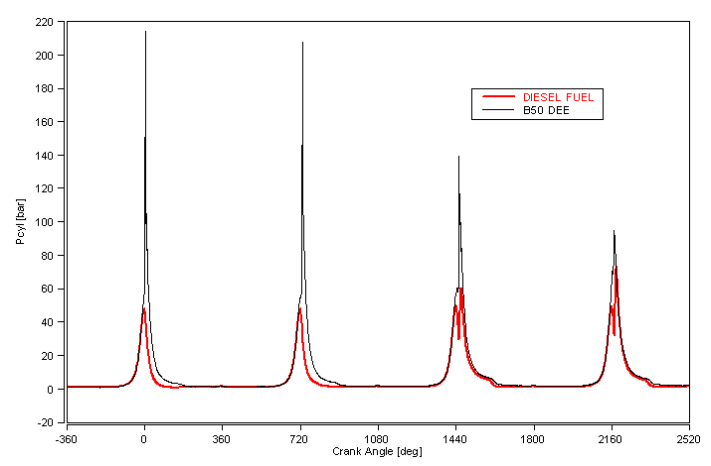

(b)

Figure 7. Succession of Engine Cycles 5-8: (a) Diesel fuel vs. B30; (b) Diesel fuel vs. B50_DEE.

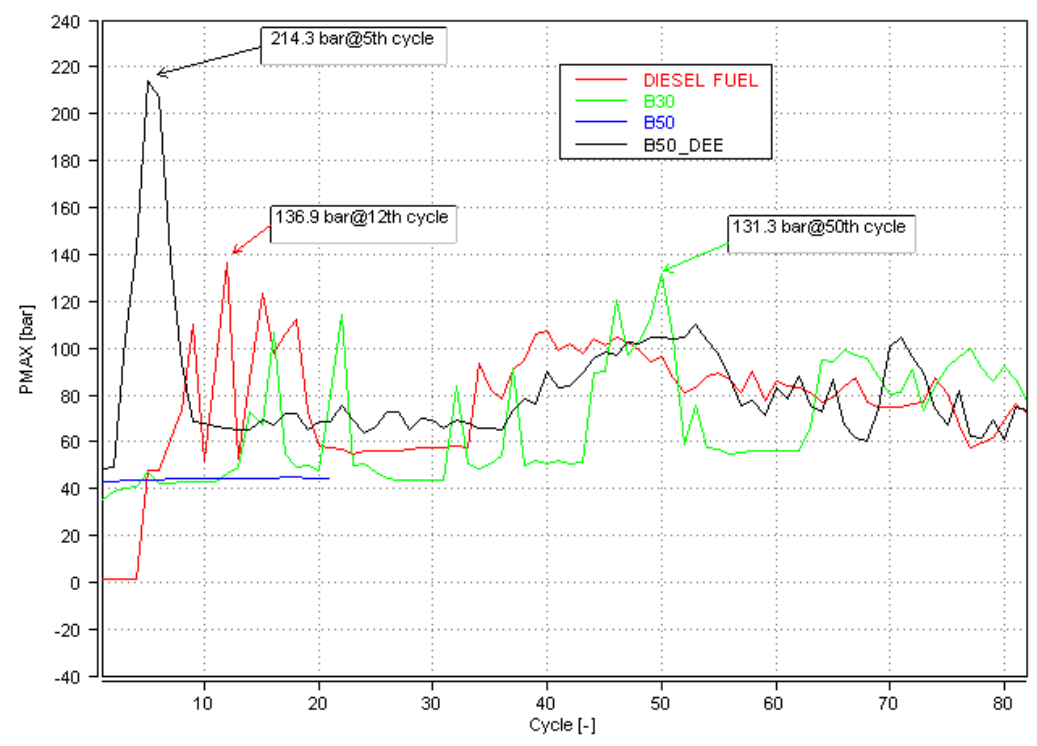

Figure 8. Pressure peaks' cyclic evolution.

Taking into account the physical properties of the DEE, these extreme peak pressures were somehow expected. However, the experiment not only proved the usefulness of DEE as the ignition improver, but also provided exact figures regarding its effect.

To assess in greater detail the deterioration of engine cold starting performance, an analysis of the number of misfire cycles and cyclic dispersion was performed over the first 200 engine cycles (i.e., during the cranking and stabilizing phases).

In order to determine the misfire cycles, it was considered that an engine cycle not producing indicated work is a cycle whose Indicated Mean Effective Pressure (IMEP) is below 0.5 bar (Figure 9). Furthermore, the cycle-to-cycle variation was evaluated through the Coefficient of Variance (CoV) applied to the IMEP and Pmax (Figure 10).

Figures 9 and 10 show a clear deterioration of engine operation on increasing the percentage of biodiesel in the resulting fuel: 15 failed engine cycles out of 200 for diesel fuel, against 25 for B30. The B50 case is as we have already seen a failure to start the engine, i.e., $100 \%$ of recorded cycles are missed.

Despite the extreme mechanical stress, DEE proves its role as ignition improver, causing the starting of the engine: the number of failed engine cycles decreases to 3 out of 200; also, the cyclic dispersion of the IMEP and Pmax decreases compared to values recorded for diesel fuel (Figure 10). 

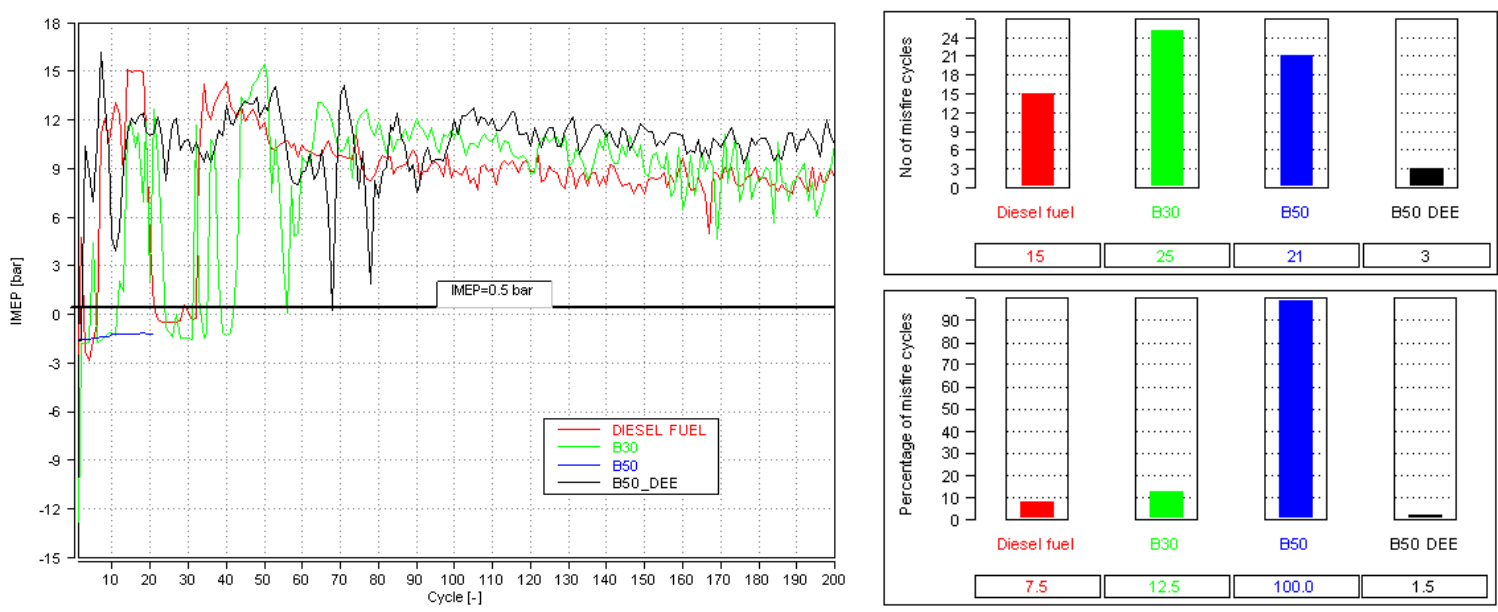

Figure 9. Misfire engine cycles.

\begin{tabular}{|c|c|c|c|c|}
\hline & $\begin{array}{l}\text { DIESEL FUEL } \\
\text { IMEP [bar] }\end{array}$ & $\begin{array}{c}\text { B30 } \\
\text { IMEP [bar] }\end{array}$ & $\begin{array}{c}\text { B50 } \\
\text { IMEP [bar] }\end{array}$ & $\begin{array}{l}\text { B50 DEE } \\
\text { IMEP [bar] }\end{array}$ \\
\hline Min & -2.9 & -12.8 & -1.5 & -1.7 \\
\hline Mean & 8.6 & 8.2 & -1.3 & 10.5 \\
\hline Max & 15.1 & 15.4 & -1.2 & 16.1 \\
\hline Cov\% & 39.2 & 54.4 & -11.0 & 21.3 \\
\hline & $\begin{array}{l}\text { DIESEL FUEL } \\
\text { Pmax [bar] }\end{array}$ & $\begin{array}{c}\text { B30 } \\
\text { Pmax [bar] }\end{array}$ & $\begin{array}{c}\text { B50 } \\
\text { Pmax [bar] }\end{array}$ & $\begin{array}{l}\text { B50 DEE } \\
\text { Pmax [bar] }\end{array}$ \\
\hline Min & 1.4 & 35.7 & 42.8 & 48.5 \\
\hline Mean & 71.5 & 72.7 & 44.2 & 87.8 \\
\hline Max & 136.9 & 131.3 & 45.0 & 214.2 \\
\hline Cov\% & 23.8 & 24.4 & 1.4 & 20.5 \\
\hline
\end{tabular}

Figure 10. Cyclic dispersion over the first 200 engine cycles.

Finally, for the 3 cases under discussion (diesel fuel, B30 and B50 with DEE injection), another analysis was performed concerning the cycle-to-cycle variation during another 200 engine cycles acquired after the initial 200 engine cycles (i.e., the idling phase); see Figure 11.

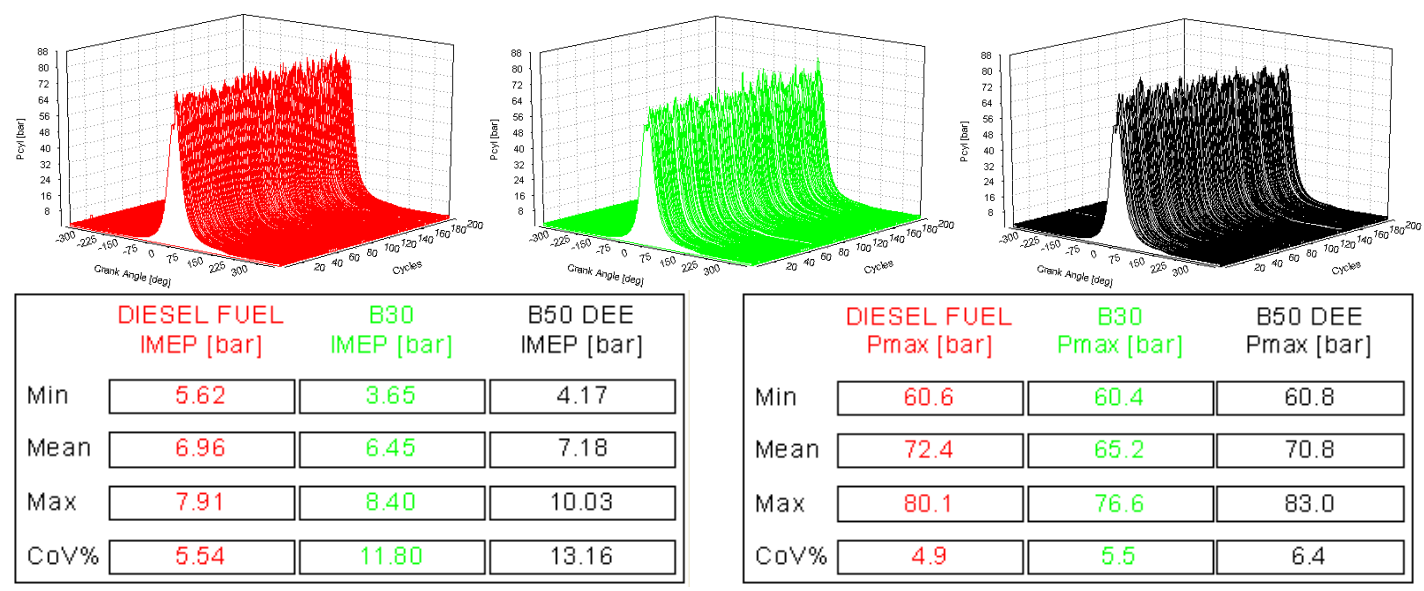

Figure 11. Cycle-to-cycle analysis during the idling stage. 
The conclusion reached during the analysis of the undershoot (Figure $5 b$ ) on the stability of engine operation that deteriorates with the addition of biofuel is also supported by the results shown in Figure 11. Even for B50 with DEE injection, the cyclic dispersion reaches maximum values on both analyses (CoV applied equally to IMEP and Pmax). This is also seen in Figure 6: the fluctuations of the fuel mass injected represent, as already mentioned, the attempt of the ECU to stabilize the engine operation. Therefore, as predicted, for the B50 case, after starting the engine with the help of DEE, more exactly, after depletion of DEE from the engine cylinders, the negative aspects of biofuel mentioned at the beginning of this article began to take over by intensifying the cyclic dispersion.

\section{Summary and Conclusions}

Since the launch of initial programs for biofuels, which followed the two oil shocks of the 1970s, the context has changed considerably. Now, biofuels have acquired a real status as complementary fuels to petroleum fuels. While biofuels can never entirely replace oil, they are used in mixtures/blends, taking advantage of existing fuel distribution networks.

Today, the biofuel for diesel engines is produced from vegetable oils obtained from different feedstocks. As vegetable oils are unsuitable for direct use in modern diesel engines, they have to be transformed through a transesterification process with an alcohol, currently methanol, which gives the methyl esters of vegetable oils or biodiesel. Biodiesel can be used pure or mixed/blended. The pure use requires adaptations of the vehicle, which limits the spread.

This paper has highlighted one of the problems encountered when blending biodiesel with commercial petroleum diesel: the deterioration of the cold starting performance of a diesel engine. This was observed by the following time-resolved parameters: instantaneous engine speed, injected fuel mass, in-cylinder instantaneous pressure and cyclic dispersion. All of these parameters were analyzed during the cranking, stabilizing and idle phases. In short, it was shown that:

- The more biodiesel is added, the poorer the engine cold starting performance will be;

- Exact data were provided to show in what way the cold starting performance was affected;

- With a biodiesel ratio of $50 \%$, the engine did not start;

- Hence, the injection of di-ethyl-ether (DEE) as a specific solution to help engine cold starting was investigated; its effect on engine operation was clearly highlighted (e.g., extreme pressure peaks, which make DEE incompatible with the use of glow plugs).

Finally, this experimental investigation was meant to show in what way different blends of biodiesel with commercial diesel fuel might be suited in countries where extreme cold weather is usually encountered. It can be said that for B30, the engine has almost no problem starting, while for higher ratio blends, different solutions for aiding the engine to start have to be found (e.g., injection of the right amount of DEE, so that engine damage is avoided).

Acknowledgments: The authors would like to express their gratitude to the Romanian Council for Scientific Research in Higher Education for their financial grant in the period 2009-2012. The authors also wish to express their appreciation to Ion Iosub from the Chemistry Department of the University of Pitesti who produced the pure biodiesel and prepared the fuels used in the tests. Thanks are also due to Renault Technologie Roumanie, which provided the cold room for the tests and helped with the characterization of the fuels used in tests.

Author Contributions: All the authors have equal contribution to the work presented in this article.

Conflicts of Interest: The authors declare no conflict of interest. 


\section{Abbreviations}

The following abbreviations are used in this manuscript:

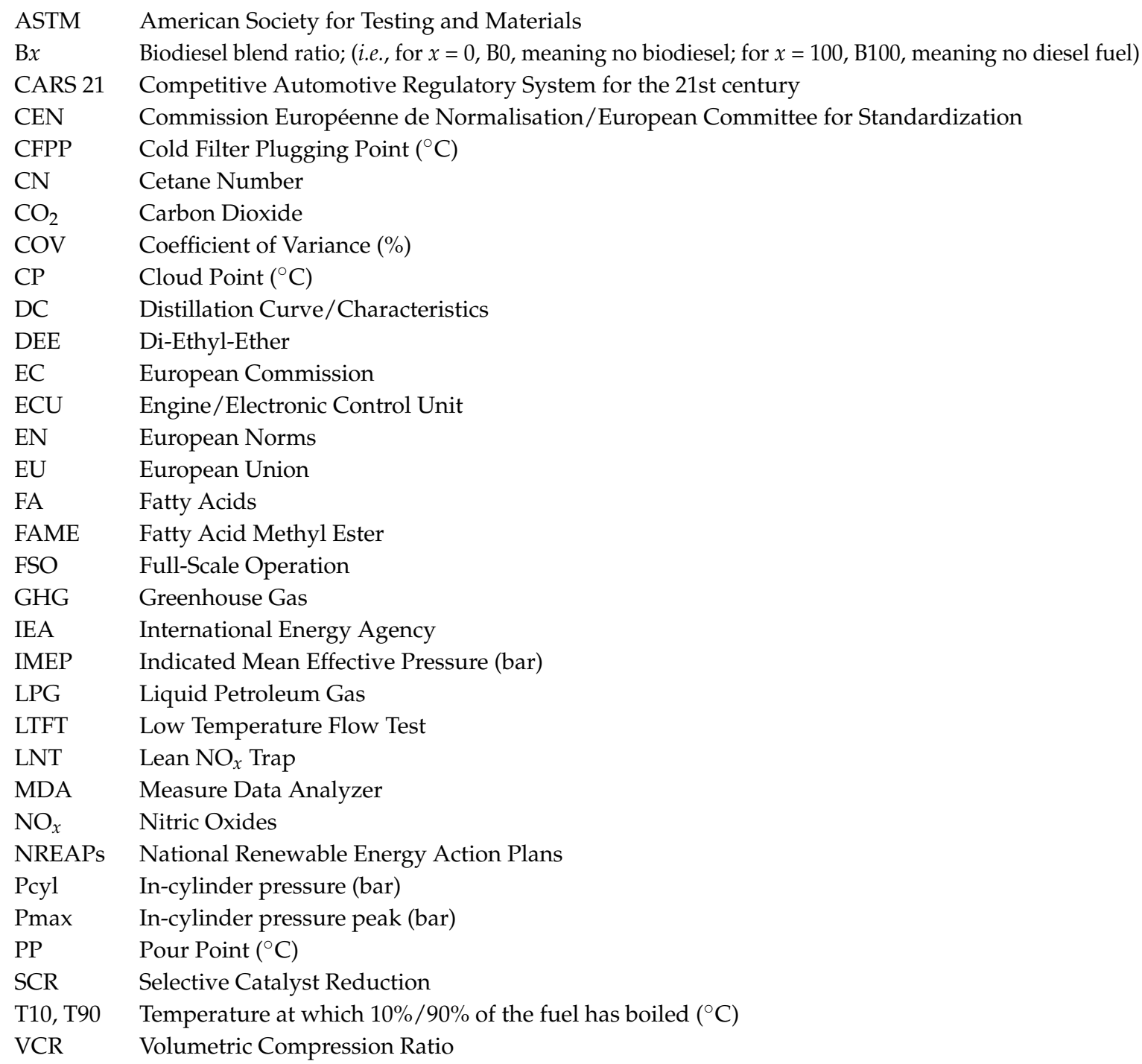

\section{References}

1. CARS 21 High Level Group. On the Competitiveness and Sustainable Growth of the Automotive Industry in the European Unio, European Commission, 2012. Available online: http://europa.eu/rapid/pressrelease_MEMO-11-862_en.htm?locale=en (accessed on 11 April 2016).

2. Escobar, J.C.; Lora, E.S.; Venturini, O.J.; Yáñez, E.E.; Castillo, E.F.; Almazan, O. Biofuels: Environment, technology and food security. Renew. Sustain. Energy Rev. 2009, 13, 1275-1287. [CrossRef]

3. European Expert Group. Report on Future Transport Fuels, European Commission, 2011. Available online: http://ec.europa.eu/transport/urban/vehicles/road/clean_transport_systems_en.htm (accessed on 11 April 2016).

4. European Commission. Clean Energy for Transport: A European Strategy on Alternative Fuels; European Commission: Brussels, Belgium, 2013.

5. European Commission. Directive 2009/28/EC on the Promotion of the Use of Energy from Renewable Sources and Amending and Subsequently Repealing Directives 2001/77/EC and 2003/30/EC, 2009, Directive 2009/28/EC); European Commission: Brussels, Belgium, 2009.

6. Hoekman, S.K.; Broch, A.; Robbins, C.; Ceniceros, E.; Natarajan, M. Review of biodiesel composition, properties, and specifications. Renew. Sustain. Energy Rev. 2012, 16, 143-169. [CrossRef] 
7. Singh, S.P.; Singh, D. Biodiesel production through the use of different sources and characterization of oils and their esters as the substitute of diesel: A review. Renew. Sustain. Energy Rev. 2010, 14, 200-216. [CrossRef]

8. Dwivedi, G.; Sharma, M.P. Impact of cold flow properties of biodiesel on engine performance. Renew. Sustain. Energy Rev. 2014, 31, 650-656. [CrossRef]

9. Atadashi, I.M.; Aroua, M.K.; Aziz, A.A. High quality biodiesel and its diesel engine application: A review. Renew. Sustain. Energy Rev. 2010, 14, 1999-2008. [CrossRef]

10. Karmakar, A.; Karmakar, S.; Mukherjee, S. Properties of various plants and animals feedstocks for biodiesel production. Bioresour. Technol. 2010, 101, 7201-7210. [CrossRef] [PubMed]

11. Murugesan, A.; Umarani, C.; Chinnusamy, T.R.; Krishnan, M.; Subramanian, R.; Neduzchezhain, N. Production and analysis of bio-diesel from non-edible oils-A review. Renew. Sustain. Energy Rev. 2009, 13, 825-834. [CrossRef]

12. American Society for Testing and Materials (ASTM). ASTM D975: Standard Specification for Diesel Fuel Oils. 2015. Available online: http://www.pdfdrive.net/astm-d975-standard-specification-for-diesel-fuel-oilse6520722.html (accessed on 11 April 2016).

13. European Committee for Standardization. Available online: https://www.cen.eu/Pages/default.aspx (accessed on 11 April 2016).

14. Worldwide Fuel Charter Committee, Biodiesel Guidelines, 2009. Available online: https://www.acea.be/ uploads/publications/20090423_B100_Guideline.pdf (accessed on 11 April 2016).

15. Gopinath, A.; Puhan, S.; Nagarajan, G. Relating the cetane number of biodiesel fuels to their fatty acid composition: A critical study. Proc. Inst. Mech. Eng. Part D J. Automob. Eng. 2009, 223, 565-583. [CrossRef]

16. Worldwide Fuel Charter Committee, Worldwide Fuel Harmonisation, 2013. Available online: https:/ / www. acea.be/uploads/publications/Worldwide_Fuel_Charter_5ed_2013.pdf (accessed on 11 April 2016).

17. Xiao, G.; Qiao, X.; Huang, Z.; Chen, Z. Improvement of startability of direct-injection diesel engines by oxygen-enriched intake air. Proc. Inst. Mech. Eng. Part D J. Automob. Eng. 2007, 221, 1453-1465. [CrossRef]

18. Lippert, A.; Stanton, D.; Reitz, R.; Rutland, C. Investigating the effect of spray targeting and impingement on diesel engine cold start. SAE Pap. 2000. [CrossRef]

19. Zahdeh, A.; Henein, N. Diesel cold starting: Actual cycle analysis under border-line conditions. SAE Pap. 1990. [CrossRef]

20. Brown, N.; Gupta, V.; la Rocca, A.; Shayler, P.J.; Murphy, M.; Pegg, I.; Watts, M. Investigations of fuel injection strategy for cold starting direct-injection diesel engines. Proc. Inst. Mech. Eng. Part D J. Automob. Eng. 2007, 221, 1415-1424. [CrossRef]

21. Niculescu, R. On the methods used in order to improve diesel startability. In Proceedings of the ESFA International Conference, Brussels, Belgium, 4-5 June 2009.

22. Broatch, A.; Tormos, B.; Olmeda, P.; Novella, R. Impact of biodiesel fuel on cold starting of automotive direct injection diesel engines. Energy 2014, 73, 653-660. [CrossRef]

23. Ali, O.M.; Mamat, R.; Najafi, G.; Yusaf, T. Optimization of biodiesel-diesel blended fuel properties and engine performance with ether additive using statistical analysis and response surface methods. Energies 2015, 8, 14136-14150. [CrossRef]

24. Ali, O.M.; Yusaf, T.; Mamat, R.; Abdullah, N.R.; Abdullah, A.A. Influence of chemical blends on palm oil methyl esters' cold flow properties and fuel characteristics. Energies 2014, 7, 4364-4380. [CrossRef]

25. Kim, J.; Yim, E.; Jeon, C.; Jung, C.; Han, B. Cold performance of various biodiesel fuel blends at low temperature. Int. J. Automot. Technol. 2012, 13, 293-300. [CrossRef]

26. Krisnangkura, K.; Yimsuwan, T.; Pairintra, R. An empirical approach in predicting biodiesel viscosity at various temperatures. Fuel 2006, 85, 107-113. [CrossRef]

27. Tziourtzioumis, D.; Demetriades, L.; Zogou, O.; Stamatelos, A.M. Experimental investigation of the effect of a B70 biodiesel blend on a common-rail passenger car diesel engine. Proc. Inst. Mech. Eng. Part D J. Automob. Eng. 2009, 223, 685-701. [CrossRef]

28. Sudheesh, K.; Mallikarjuna, J.M. Diethyl ether as an ignition improver for biogas homogeneous charge compression ignition (HCCI) operation-An experimental investigation. Energy 2010, 35, 3614-3622. [CrossRef] 
29. Rakopoulos, D.C.; Rakopoulos, C.D.; Giakoumis, E.G.; Papagiannakis, R.G.; Kyritsis, D.C. Influence of properties of various common bio-fuels on the combustion and emission characteristics of high-speed DI (direct injection) diesel engine: Vegetable oil, bio-diesel, ethanol, N-butanol, diethyl ether. Energy 2014, 73, 354-366. [CrossRef]

30. Cinar, C.; Can, Ö.; Sahin, F.; Yucesu, H.S. Effects of premixed diethyl ether (DEE) on combustion and exhaust emissions in a HCCI-DI diesel engine. Appl. Therm. Eng. 2010, 30, 360-365. [CrossRef]

31. Mattarelli, E.; Rinaldini, C.A.; Savioli, T. Combustion analysis of a diesel engine running on different biodiesel blends. Energies 2015, 8, 3047-3057. [CrossRef]

(C) 2016 by the authors; licensee MDPI, Basel, Switzerland. This article is an open access article distributed under the terms and conditions of the Creative Commons Attribution (CC-BY) license (http:/ / creativecommons.org/licenses/by/4.0/). 